\title{
EL SENTIDO CIENTIFICISTA DE LA "INVESTIGACIÓN" DESDE EL POSITIVISMO de Augusto Comte
}

\author{
THE SCIENTISTIC SENSE OF "RESEARCH" \\ FROM THE POSITIVISM OF AUgUSTE COMTE
}

A ngele Kremer - Mariette señala en su libro El positivismo:

Por primera vez con Augusto Comte la filosofía abandonó la teoría del conocimiento tradicional por una teoría de la ciencia. Más precisamente: una teoría de la ciencia entendida como el producto de la sociedad en su historia ${ }^{1}$.

Con estas palabras se confirma la intención cientificista de la filosofía de Comte y su intrínseca relación con las distintas disciplinas que estudian la sociedad. En la obra titulada Discurso sobre el espíritu positivo, Comte propone la ley de los tres estados como pieza angular de su sistema científico y social. En la obra se muestra un cuadro ordenado de la evolución del espíritu humano (teológico, metafísico y positivo) el cual concluye, después de un largo proceso maduración intelectual, en el positivismo (pensamiento filosófico que afirma que el conocimiento auténtico es el conocimiento científico). El cientifismo formulado por Comte concibe a la ciencia como un saber sólido y ajustado a la razón, que excluye a la metafísica y la teología consideradas como estados anteriores a la primacía de la razón. En este sentido, la filosofía de Comte apunta a una filosofía de la ciencia y la razón, al triunfo de la "razón científica". Los tres estados corresponden no sólo aun método de filosofar, sino además, aún progreso necesario de la humanidad, que históricamente debe desarrollarse hasta alcanzar el estado positivo. Como afirma Kremer - Mariette (1989), “Así, desde el principio, la ciencia positiva estuvo en parte ligada con el progreso temporal, es decir con la historia" (p.15).

En este sentido, el positivismo sabe hacer justicia con los estados anteriores de conocimiento, en virtud de su relativismo, es decir, debido a su concepción de la "verdad" como histórica. Desde el positivismo no ha habido en la historia errores, sino sucesivas aproximaciones al estado positivista. Se debe concluir que el estado positivo es el estado final de la evolución de la humanidad. La ley de la evolución intelectual de la humanidad es fácilmente demostrable a partir de la historia misma, en donde el proceso evolutivo corresponde a tres periodos histórico que son: 1. infancia- teológico, 2. juventud- metafísico, y 3. madurez- científico.

En este orden de ideas, la Revista Inclusión y Desarrollo responde a una publicación de carácter científico que tiene como objetivo pro- 
mover la difusión de las investigaciones en el campo de las ciencias sociales y en particular en el área de la inclusión y el desarrollo social. En este Vol. 5 \# 2 -2018 (julio-diciembre) se publican once artículos de investigación y revisión que dan cuenta de resultados de investigación desde diferentes campos de saber social y que contribuyen a la consolidación de un corpus teórico sólido desde las ciencias sociales y humanas. Los artículos son:

1.“Ética en Platón y Moore: relación con la movilización social y la acción colectiva", donde se pretende encontrar una relación entre le ética y la acción colectiva, de tal manera que la reflexión ética se constituya en una estrategia para la movilización social.

2."El Scratch como estrategia didáctica para desarrollar la exploración del medio en la educación inicial -Fase I y II-“, se da a conocer los resultados de la investigación "El Scratch como estrategia didáctica para desarrollar la exploración del medio en la educación inicial”.

3. “Ciudadanía restringida delas mujeres víctimas del conflicto armado en Colombia debido a las barreras de acceso a lajusticia", hace una teorización en los temas de ciudadanía y acceso a la justicia a partir del enfoque de derechos humanos, evidenciando la articulación que existe entre estos componentes.

4. “Manejo de tecnología e información científica en la formación universitaria", presenta los resultados de una investigación que se realizó entre agosto y diciembre de 2014, con el objetivo de demostrar que una Propuesta didáctica que incluye el uso de herramientas tecnológicas desarrolla, la habilidad del manejo de la tecnología y la información científica en estudiantes del nivel superior; el diseño de investigación asumido fue el denominado pre experimental.

5."Estilos de enseñanza y desarrollo de competencias investigativas en educación superior", donde se da cuenta del camino seguido por tres profesores de cátedra de la Universidad de La Salle, que indagaron por los estilos de enseñanza de algunos maestros y las competencias investigativas de sus respectivos estudiantes con el objeto de caracterizar los primeros e identificar las segundas, evidenciando cuáles estilos docentes promueven en mayor o menor grado las diversas competencias de investigación a través de su práctica en el aula.

6.“Creando y sintiendo” Prácticas artísticas para la construcción de cultura de paz", muestra las relaciones encontradas entre educación, cultura de paz y las artes plásticas, a partir de las percepciones de los estudiantes de educación media de la jornada tarde, en el colegio Nueva Delhi, con quienes se desarrolló un proceso reflexivo sobre diferentes manifestaciones de violencia y construcción de cultura de paz.

7."Proyecto de Traducción del navegador Firefox a la lengua nasa: un paso en la inclusión digital", se da a conocer una iniciativa que promueve la inclusión digital de los hablantes de la lengua nasa: se presenta el proceso llevado a cabo con los traductores de esta lengua durante la ejecución del proyecto Traducción del navegador Firefox 
para Android y de Firefox OS a tres lenguas indígenas de Colombia habladas en Bogotá.

8.“Discapacidad y calidad de vida en población adulta del Municipio de Soledad, Atlántico - Colombia”, presenta la relación entre discapacidad y calidad de vida en personas adultas del municipio de Soledad, Atlántico (Colombia).

9."Actitudes hacia la discapacidad en educación superior", corresponde a un estudio para identificar las actitudes de los profesores universitarios hacia la discapacidad.

10.“El trabajo infantil como reto de la inclusión educativa desde las representaciones sociales de la escuela: caso de la Institución Educativa Andrés Bello - Sede Laura Vicuña - Cúcuta”, permite comprender las representaciones sociales de los maestros de la I.E. Andrés Bello - Sede Laura Vicuña de la ciudad de Cúcuta, acerca del trabajo infantil (TI).

Finalmente el artículo aporte de semilleros de investigación, “Diseño de rutas seguras como alternativa de intervención al riesgo público para los docentes de colegios del sector público y privado de la localidad de Ciudad Bolívar", donde se analizan las diversas problemáticas del riesgo público, al cual están expuestos los docentes en los centros educativos: Colegio el Minuto de Buenos Aires y Colegio Confraternidad de San Fernando en la localidad de Ciudad Bolívar de la ciudad de Bogotá 